extensive than that of Professor Young. io such persons the set of exercises and questions based on each chapter should also prove useful. In spite of the wideness of the subject and the soundness of its scientific and factual approach, the manner is not involved, and the book remains comparatively easy reading without incurring the slightest risk of being dubbed "popular" in the less desirable sense of the term.

\section{I. DunsDon.}

The Single Woman and Her Emotional ProbLEMS. By Laura Hutton, B.A., M.R.C.S., L.R.C.P., Physician, Institute of Medical Psychology. With a Foreword by David Forsyth, M.D., D.Sc., F.R.C.P. Balliere, Tindall and Cox. 5/-.

This little book, of only 157 small pages, makes an important contribution to the literature of Mental Health on a subject but rarely discussed.

The writer reveals a deep understanding and a sensitive appreciation of the urgency of a fundamental human problem which is becoming increasingly common, and she does not hesitate to write of it in all its aspects-physical as well as emotional and mental-her treatment of it being at once restrained and fearless.

The chapter on Emotional Friendships should be particularly illuminating to those who are not afraid to face up to the challenge it presents, and the chapter on Sexual Inversion should help towards a better understanding on a topic about which such widespread ignorance and misconception exists.

In the final chapter, there is a plea for a change in the attitude of the community towards the single woman, and the book ends on a stimulating note of encouragement and hope.

\section{A.L.H.}

\section{MENTAL WELFARE LIBRARY.}

The Library contains an up-to-date supply of book: serviceable to teachers of defective children, and to mental welfare workers.

Subscription, 10/- per annum (postage extra).

Interleaved Catalogue, price $6 \mathrm{~d}$.

For further information, apply to The Librarian, 24, Buckingham Palace Road, S.W.1.

\section{List of Additions to the Library.}

Blanton, S. \& M. G. For Stutterers. 1936.

Buehler, C. Testing Children's Development from Birth to School Age. 1935.

Gregory, A. Constructive Woodwork for Schools. 2nd Edition. 1936.

Jung, C. Modern Man in Search of a Soul. 1934.

KNIGHT, REx. Intelligence and Intelligence Tests. 1933.

McFie Campbell. Destiny and Disease in Mental Disorders. 1935.

Ross, T. A. An Enquiry into the Prognosis in the Neuroses. 1936.

\section{Bibliography}

$\dagger$ Twentieth Century Psychiatry. Its Contribution to Man's Knowledge of Himself. By Wm. A. White, M.D. Chapman \& Hall. 10/6.

†Essentials of Psycho-Pathology. By Geo. W. Henry, Associate Professor of Psychiatry, Corneli University Medical School, U.S.A. Balliere, Tindall \& Cox. 18/-.

Mental Health. By Frank E. Howard, Ph.D., Professor of Education and Psychology; and Fredk. L. Patry, M.D., Psychiatrist, State Education Department, University of the State of New York. Harper \& Bros. 15/-.

Mental Nursing Simplified. By O. P. Napier PEARN, M.R.C.S., L.R.C.P., D.P.M. 2nd Edition. Balliere, Tindall \& Co. $5 /$ -

An Enquiry into the Prognosis in the Neuroses. By T. A. Ross, M.D., F.R.C.P. Cambridge University Press. 10/6.

* The Single Woman and Her Emotional Problems. By Laura Hutton, B.A., M.R.C.S., L.R.C.P. Balliere, Tindall \& Cox. 5/-.

A Study of Masturbation and the Psycho-Sexual. LIFE. By John F. W. Meagher, M.D., F.R.C.P. 3rd Edition. Re-edited and Revised by Smith Ely Jelliffe, M.D., Ph.D. Balliere, Tindall \& Cox. $8 / 6$.

† Medical Aspects of Crime. By W. Norwood East. With Foreword by the Rt. Hon. Sir John Simon. J. \& A. Churchill. 18/-.

* Motivation of Behaviour. By Paul Thomas Young, Professor of Psychology in the University of Illinois. Chapman \& Hall. 20/-.

Psychology from the Standpoint of a BehaviourIST. By John B. Watson. 3rd New and Revised Edition. J. B. Lippincott \& Co. 12/6.

*Adolescence. By L. A. Averill, Head of the Department of Psychology, State Teachers College, Worcester, Mass. Harrap \& Co. 8/6.

The Psychology of Adjustment. An 'Objective Approach to Mental Hygiene. By L. F. Shaffer, Ph.D., Associate Professor of Psychology, Carnegie Institute of Technology. Harrap. 10/6. 